\title{
Panoramic Radiography and Cone Beam Computed Tomography in the Early Diagnosis of Atheroma in the Extracranial and Intracranial Internal Carotid Artery: A Case Report
}

\author{
Radiografía Panorámica y Tomografía Computarizada de Haz Cónico en el Diagnóstico Pre- \\ coz de Ateroma en la Arteria Carótida Interna, Extracraneal e Intracraneal: Reporte de Caso
}

\author{
Eduardo Murad Villoria1; Bernardo Quiroga Souki'; Flávio Lucena Antunes ${ }^{1}$; \\ Isis Kanitar Castro²; Kyria Spyro Spyrides ${ }^{3}$ \& Rodrigo Villamarim Soares ${ }^{1}$
}

VILLORIA, E. M.; SOUKI, B. Q.; ANTUNES, F. L.; CASTRO, I. K.; SPYRIDES, K. S. \& SOARES, R. V. Panoramic radiography and cone beam computed tomography in the early diagnosis of atheroma in the extracranial and intracranial carotid artery: A case report. Int. J. Odontostomat., 13(1):75-81, 2019.

ABSTRACT: Carotid stenosis usually results from the accumulation of atherosclerotic plaque in the carotid artery wall and is an important risk factor for ischemic cerebral vascular accident (CVA). This study describes the importance of diagnostic imaging exams used in dentistry for the early identification of atheroma plaques in the extracranial and intracranial internal carotid artery. A male patient was referred to a radiology clinic to perform panoramic radiography (PR) and a cone beam computed tomography (CBCT) to develop treatment plan options. In the PR and CBCT a radiopaque image, suggestive of atheroma in the extracranial internal carotid artery, was observed on the right side. The diagnosis was confirmed by color DOPPLER ultrasonography. In the $\mathrm{CBCT}$, the presence of calcifications in the intracranial internal carotid artery was also observed. Diagnostic imaging exams used in dentistry allow the identification of asymptomatic individuals, facilitating early intervention and consequent reduction in the risk of ischemic CVA.

KEY WORDS: cone beam computed tomography, panoramic radiography, color doppler ultrasonography, atherosclerosis.

\section{INTRODUCTION}

Carotid stenosis is an important risk factor for ischemic cerebral vascular accident (CVA) (Ritter \& Tyrrell, 2013). Stenosis usually results from the accumulation of atherosclerotic plaque in the carotid artery wall, causing luminal reduction and thromboembolization (Rothwell et al., 2003). Hypertension, dyslipidemia, diabetes mellitus, cardiovascular diseases, smoking and menopause are some of the risk factors for the development of atheroma plaque and cerebral vascular accident (Friedlander \& Altman, 2001; Friedlander et al., 2002; Tamura et al., 2005; Ardakani et al., 2007; Griniatsos et al., 2009).
CVA are subdivided into hemorrhagic and ischemic. Hemorrhagic CVAs are caused by a rupture in a weakened blood vessel, correspond to $15 \%$ of the CVAs, and display predilection by the intracranial vessels. Consequently, approximately $85 \%$ of CVAs occur when an atherosclerotic plaque occludes the lumen of a vessel, resulting in distal ischemia due to obliteration. Ischemic CVAs originate from plaques formed at the common carotid artery bifurcation. The plaque develops when cholesterol, platelets, cellular products and calcium are deposited on the internal wall of the common carotid artery (Manzi et al., 2003). The CVA occurs when the atherosclerotic plaque, or the

\footnotetext{
${ }^{1}$ School of Dentistry, Graduate Program in Dentistry, Pontificial Catholic University of Minas Gerais, Belo Horizonte, MG, Brazil.

${ }^{2}$ School of Dentistry, Unigranrio University, Rio de Janeiro, RJ, Brazil.

${ }^{3}$ Private Practice, Rio de Janeiro, RJ, Brazil.
} 
rupture of a vessel, stops the blood supply to the brain, cutting off the supply of oxygen and nutrients, causing brain tissue damage. The middle cerebral artery, a direct continuation of the internal carotid artery, is considered the most likely vessel to be obstructed by embolus originated from the common carotid artery bifurcation (Friedlander \& Gratt, 1994; Carter et al., 1997).

As soon as the atherosclerotic lesions are partially calcified, they can be observed in panoramic radiography (PR) and cone beam computed tomography (CBCT). The atherosclerotic plaque in the common carotid artery bifurcation is visualized in the cervical soft tissue region anteriorly and laterally to the anterior tubercle of the transverse process of the cervical vertebrae, laterally to the major horn of the hyoid bone, posteriorly and laterally to the pharyngeal air space, below the mandibular angle and adjacent to $C 3$, C4 and C5 vertebrae (Damaskos et al., 2015). CBCT examination of the extended skull also allows the visualization of calcifications in the intracranial internal carotid artery, with the middle fossa of the skull being the most common location (Pette et al., 2012; Friedlander et al., 2014). However, PR and CBCT are limited only to the identification of the atheroma and did not allow to evaluate its exact location and degree of obliteration (Manzi et al.; Ardakani et al.; Griniatsos et al.).

In this regard, angiographic contrasts are also used to confirm the plaques presence and to evaluate the degree of carotid artery stenosis. However, the high cost, potential for serious sequels development and limited information stimulated the development and use of other noninvasive imaging techniques, such as the color DOPPLER ultrasonography (Friedlander \& Gratt; Carter et al.).

The aim of the present study was to describe, from a clinical case, the importance of diagnostic imaging exams used in dentistry for the identification of atheroma plaques in the extracranial and intracranial internal carotid arteries.

\section{CASE REPORT}

A male patient, 77 years old, was referred to a private radiology clinic for $\mathrm{PR}$ and $\mathrm{CBCT}$ in order to evaluate teeth and dental implants and develop treatment plan options. The PR was performed using the Instrumentarium OP200D (Instrumentarium Dental, Tuusula, Finland) with 66-85 kVp, 10-16 mA, and an exposure time of 14.1 seconds. The CBCT was performed using the i-CAT Classic device (Imaging Sciences International, Hatfield, PA, USA). The tomographic acquisition was performed using a FOV of $13 \times 6 \mathrm{~cm}, 0.3 \mathrm{~mm}$ isotropic voxel, $120 \mathrm{Kv}, 8 \mathrm{~mA}$, and an exposure time of 40 seconds.

Radiographic and tomographic exams showed a radiopaque image located below the right jaw angle, adjacent to the cervical spine region and above the hyoid bone, suggestive of atheroma in an extracranial internal carotid artery bifurcation (Figs. 1 and 2). CBCT sections of the skull revealed the presence of hyper dense images located near the sella turcica, suggestive of calcification in the cavernous segment of the intracranial internal carotid artery on both sides (Figs. 3, 4 and 5).

After identification of the radiopaque/hyperdense images on the radiographic and tomographic exams, the patient was referred for medical consultation. In order to confirm the diagnosis of atheroma, evaluate the atheroma plaque, blood flow and degree of stenosis of the artery, a color DOPPLER ultrasonography of the extracranial internal carotid arteries was indicated.

The color DOPPLER ultrasonography was performed using the Philips ATL device (model HDI 3500, Philips, Botheu, WA, USA). The presence of focal, eccentric, heterogeneous and irregular plaques (Figs. 6A, B, C) was observed in the right proximal internal branch (RIB), right common carotid artery (RCC) and left common carotid artery (LCC). However, the plaques present in the right common carotid artery were echogenic (presence of acoustic shadow adjacent to the atheroma image), while the plaques present in the left common carotid are echolucent (absence of acoustic shadow). Flows with normal characteristics and velocities, compatible with obstructions of less than 50 $\%$ were observed in both arteries (Figs. 6D, E, F, G).

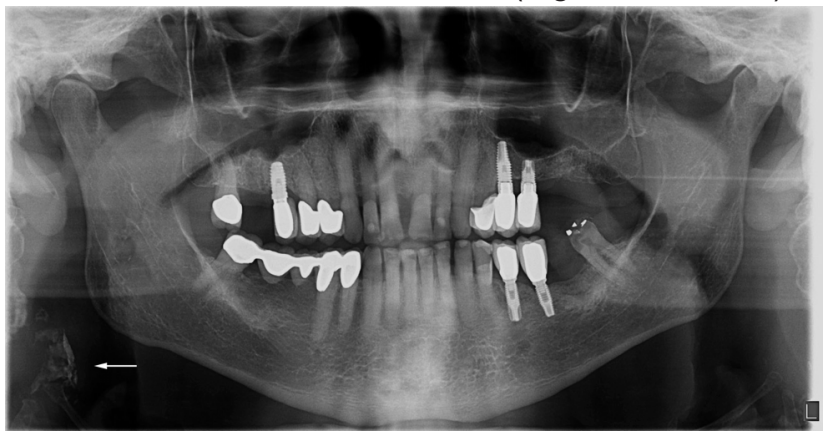

Fig. 1. Digital panoramic radiography. Radiopaque image adjacent to the cervical spine and above the hyoid bone, on the right side, suggestive of calcification in the right common carotid artery (arrow). 

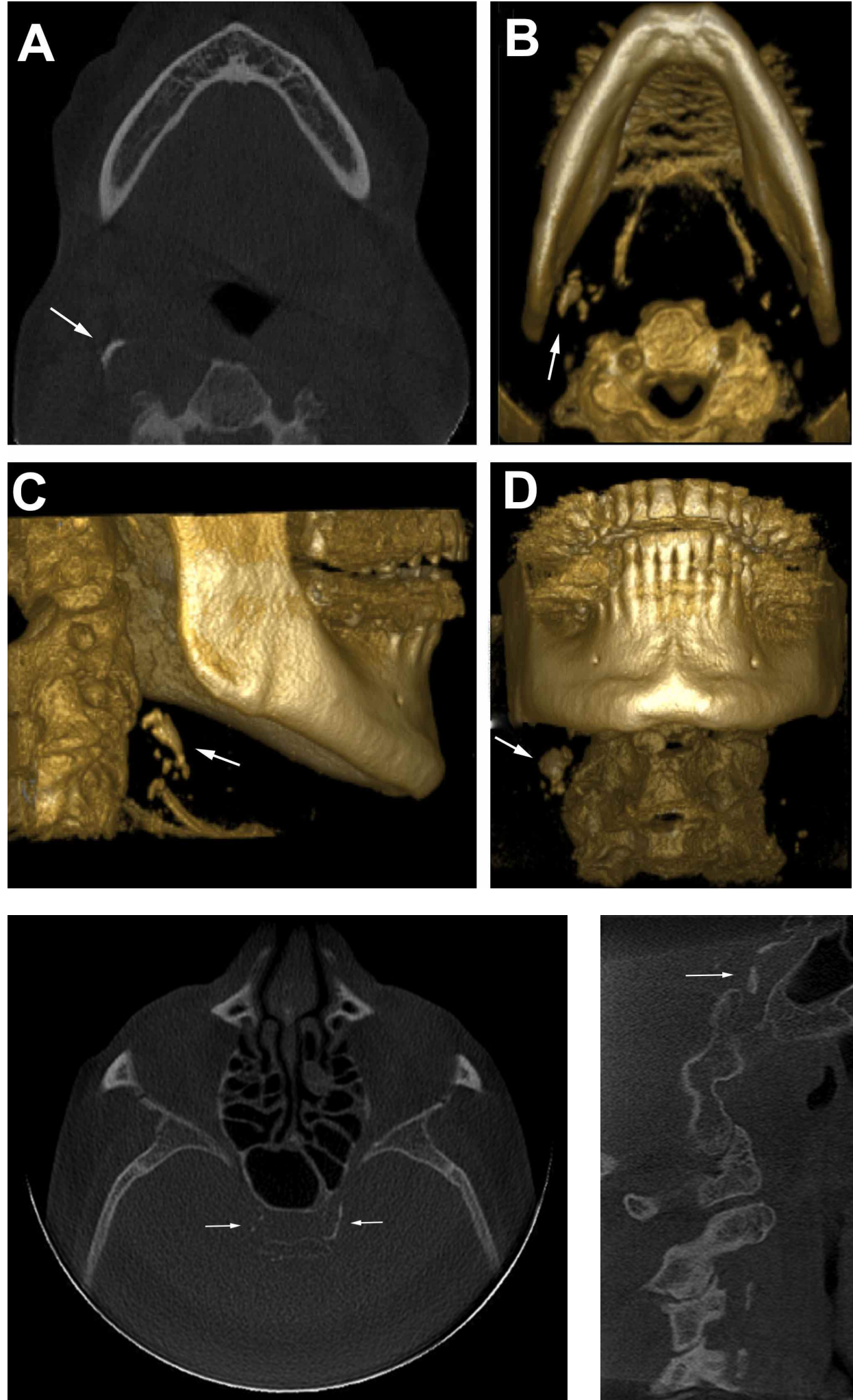

Fig. 3. Axial section of the CBCT. Presence of hyperdense image, near the sella turcica, suggestive of calcification in the cavernous segment of the right and left intracranial internal carotid artery (arrows).

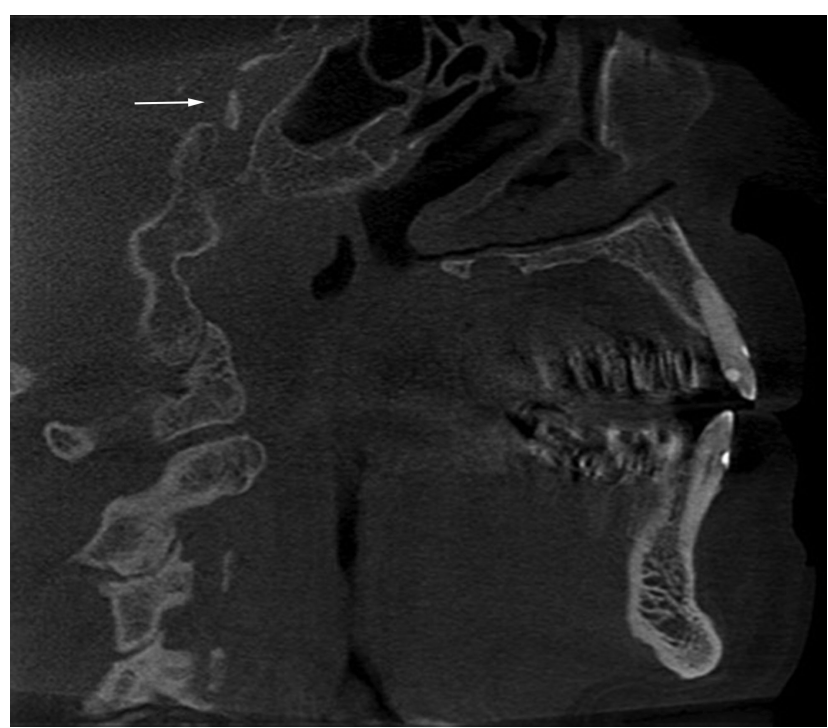

Fig. 4. Sagittal section of the CBCT. Presence of hyperdense image, near the sella turcica, suggestive of calcification in the cavernous segment of the left intracranial internal carotid artery (arrow).
Fig. 2. Axial section and 3D volumetric reconstruction of the CBCT. Presence of hyperdense image adjacent to the cervical spine (C3 and C4) and above the hyoid bone, on the right side, suggestive of calcification in common carotid artery bifurcation (arrows). 


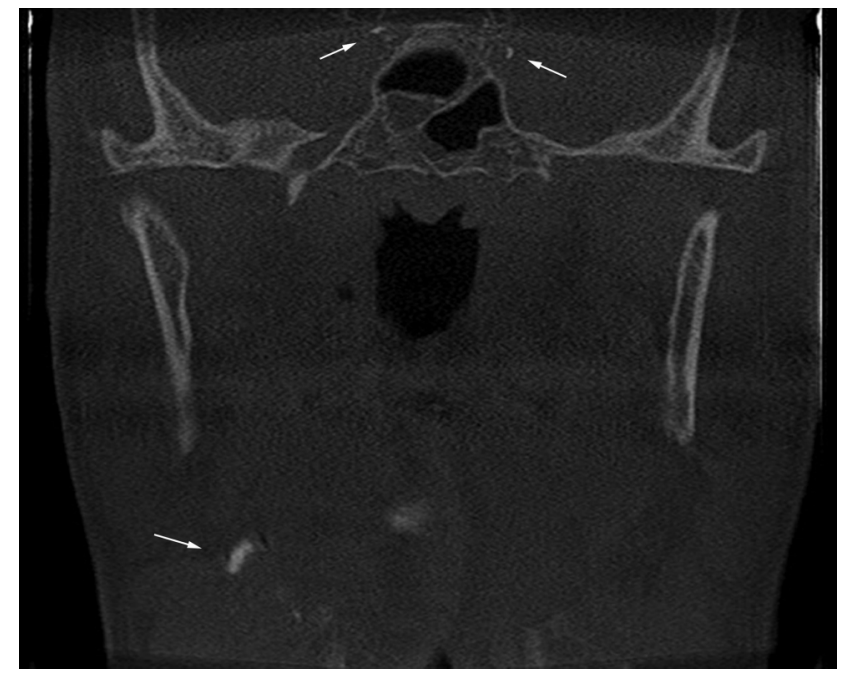

Fig. 5. Coronal section of the CBCT. Presence of hyperdense image, near the sella turcica, suggestive of calcification in the cavernous segment of the right and left intracranial internal carotid artery (arrows). A hyperdense image below the right mandibular angle, in the neck region, suggestive of calcification in the right common carotid artery is observed (arrow).

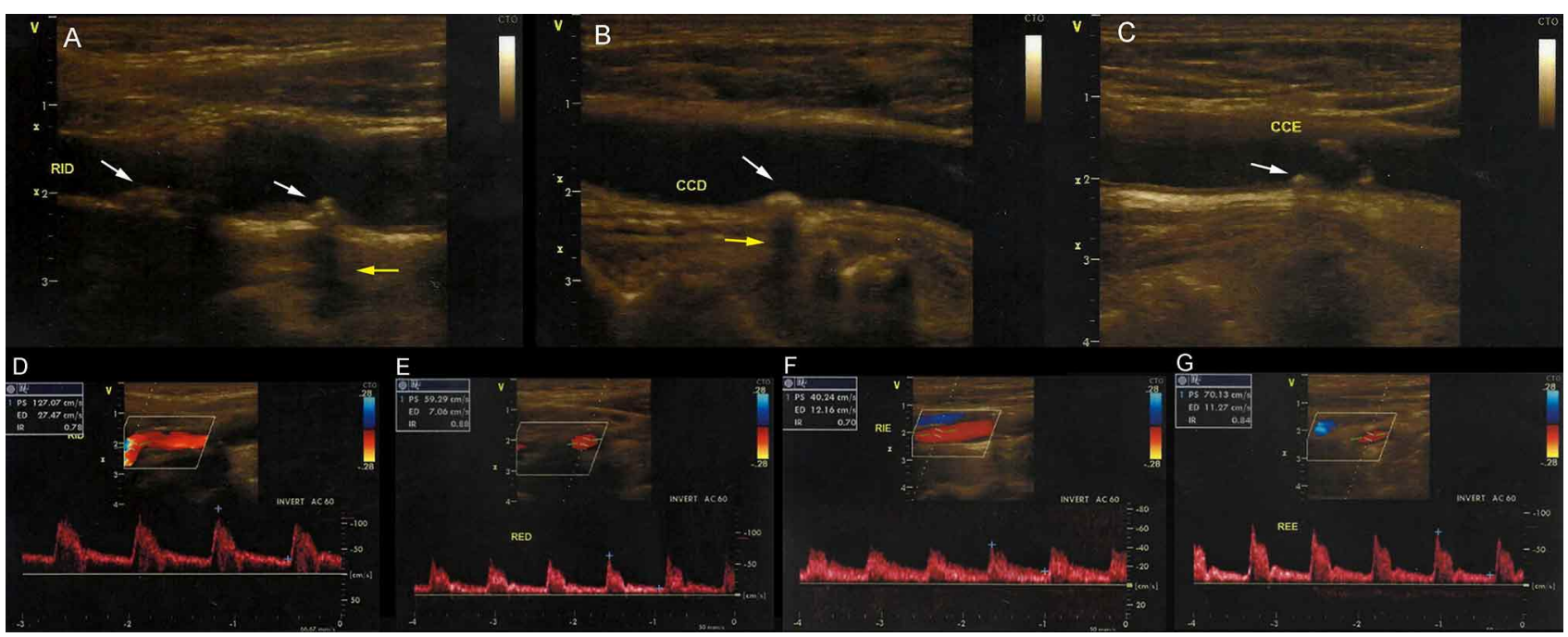

Fig. 6. DOPPLER Ultrasonography. (A and B) Longitudinal sections of the right proximal internal branch and right common carotid, showing the presence of echogenic plaques (white arrows) and acoustic shadow (yellow arrows). (C) Longitudinal sections of the left common carotid exhibiting the presence of echolucent plaques (white arrow). (D, E, F and G) Blood flow with normal characteristics and velocities, compatible with obstructions inferior to $50 \%$ in the internal and external branches of the arteries on both sides. RCC (right common carotid artery); LCC (left common carotid artery); RIB (right proximal internal branch); REB (right proximal external branch); LIB (left proximal internal branch); LEB (left proximal external branch).

\section{DISCUSSION}

In the present study it was possible to identify the presence of calcifications in the extracranial and intracranial internal carotid arteries through PR and CBCT exams. The evaluation of atherosclerotic plaque echogenicity was conducted by color DOPPLER ultrasonography. According to Griniatsos et al., based on ultrasonography tests, atheromatous plaques are classified as echogenic (abundant in calcium and fibrous tissue) and echolucent (abundant in fat, elastic and hemorrhagic component). The ultrasonography allowed differentiation of these plaques through visualization of the hypoechoic image called "acoustic shadow" that appears adjacent to the echogenic plaques. Although PR and CBCT are capable of identifying the presence of plaques with calcified components, these methods may not allow the identification of the less abundant in calcium echolucent plaques. 
VILLORIA, E. M.; SOUKI, B. Q.; ANTUNES, F. L.; CASTRO, I. K.; SPYRIDES, K. S. \& SOARES, R. V. Panoramic radiography and cone beam computed tomography in the early diagnosis of atheroma in the extracranial and intracranial carotid artery: A case report. Int. J. Odontostomat., 13(1):75-81, 2019.

The echogenic plaque is more associated with asymptomatic patients and with a lower incidence of ischemic CVA, when compared to the echolucent plaque (Rothwell et al.). This is due to the fact that echogenic plaques are likely to have much fibrous component and these are considered to be stable (Falk et al., 1995). In the present study, the color DOPPLER ultrasonography confirmed the presence of echogenic plaque in the right extracranial internal carotid artery, and demonstrated the existence of an echolucent plaque in the left extracranial internal carotid artery. Therefore, in cases where PR or CBCT demonstrate the presence of the echogenic plaque in only one of the carotid arteries, it is extremely important that the color DOPPLER ultrasonography investigates the presence of possible echolucent plaques in other regions of the same artery, as well as in the artery that did not present calcifications in the radiographic examination.

The majority (99\%) of atherosclerotic plaques present some percentage of calcification, $76 \%$ of these are located in the common carotid artery bifurcation and can be visualized in PR (Garoff et al., 2015). A positive correlation between a radiopaque image suggestive of calcification in the common carotid artery through PR, the diagnosis of thickening of the arterial intima layer and of the atherosclerotic plaque through ultrasonography, demonstrating that PR is considered a method capable of identifing the existence of atherosclerosis in the common carotid artery (Lee et al., 2014). In this regard, a previous study reported that PR had $79.8 \%$ of sensitivity and $80.1 \%$ of specificity for atheroma identification (Ertas \& Sisman, 2011).

To identify calcifications in the common carotid artery, professionals must have a broad knowledge of anatomy, since differential diagnoses from other conditions such as calcification of the superior horn of the thyroid cartilage, calcification in cervical lymph nodes, calcification of the triticeous cartilage, calcification of the styloid ligament, phlebolith and sialolithiasis in submandibular salivary gland should be established (Silva et al., 2012). Particularly, the calcification of the triticeous cartilage is the main differential diagnosis of the atheroma in the common carotid artery bifurcation observed in PR, since it presents as single or multiple radiopaque nodular structures, located near C3 and C4 cervical vertebraes (Ahmad et al., 2005; Silva et al.).

The triticeous cartilage is a bilateral ovoid structure that forms part of the laryngeal skeleton, located in the lateral thyroid ligament, between the superior horn of the thyroid cartilage and the major horn of the hyoid bone (Ahmad et al.). According to Ahmad et al., the shape and location allow differentiation between the calcification of the triticeous cartilage and atheromatous plaque in PR. This differentiation can also be performed with the assistance of anteroposterior radiographs and CBCT (Silva et al.; Almog et al., 2013). Therefore, since calcification of the triticeous cartilage will necessarily appear as a radiopaque image below the hyoid bone, in the present study, the hypothesis of this alteration was discarded, since the radiopaque image suggestive of atheroma was located above this anatomical structure.

Knowledge of the morphology and localization of calcifications in the common carotid artery assist in its diagnosis (Pette et al.). Although PR and CBCT allows the visualization of calcifications in the extracranial internal carotid artery, these exams do not determine the relationship between the volume of calcification observed with the degree of stenosis of the artery. For this purpose, regardless of the size of the calcification, the color DOPPLER ultrasonography is considered the gold standard exam since it allows the visualization of the plaque inside the artery, evaluation of the degree of artery stenosis and blood flow (Carter et al.; Manzi et al.; Pette et al.).

CBCT of the extended skull, which had its first report in dental practice in 1998, is more accurate than PR in detecting arterial calcifications and allows the identification of a greater number of pathologies due to the greater field of view and multiplanar reconstruction (Friedlander et al., 2014). Previous studies have evaluated the association between calcifications in the extracranial and intracranial internal carotid artery through CBCT of extended-cranial of adult patients, and concluded that calcification in the extracranial internal carotid artery increases the chance of the intracranial calcifications (Pette et al.; Damaskos et al.). The most common location of these calcifications in the intracranial internal carotid artery is in the middle fossa of the cranium (Pette et al.; Friedlander et al., 2014), a result that was encountered in the present case report, since in addition to extracranial internal carotid atheroma, hyperdense images located near the sella turcica, suggestive of calcification in the cavernous segment of the intracranial internal carotid artery on both sides were observed.

Visualization of calcifications in the intracranial internal carotid artery through CBCT contribute to more 
accurate medical treatment strategies since this findings are considered risk markers for development of advanced stenotic disease of the cerebral and cardiovascular circulation, cerebral deterioration and also indicator of future systemic events (Friedlander et al., 2014). In addition to CT, other neuroimaging modalities are commonly required to confirm the diagnosis and to evaluate the extent of stenosis, such as transcranial Doppler whith uppercase and contrast magnetic resonance (Friedlander et al., 2014).

In conclusion, PR can demonstrate the presence of atheroma only in the extracranial internal carotid artery and CBCT may be able to demonstrate the presence of calcification in the extracranial and intracranial internal carotid arteries. The diagnosis of atheroma plaque in the right extracranial internal carotid artery was confirmed by color DOPPLER ultrasonography. Diagnostic imaging exams used in dentistry allow the identification of asymptomatic individuals, facilitate early detection and consequent reduction in the risk of developing ischemic CVA, and therefore may reduce patient morbidity and mortality.

VILLORIA, E. M.; SOUKI, B. Q.; ANTUNES, F. L.; CASTRO, I. K.; SPYRIDES, K. S. \& SOARES, R. V. Radiografía panorámica y tomografía computarizada de haz cónico en el diagnóstico precoz de ateroma en la arteria carótida extracraneal e intracraneal: Reporte de Caso. Int. J. Odontostomat., 13(1):75-81, 2019.

RESUMEN: La estenosis carotídea generalmente es consecuencia de la acumulación de placa aterosclerótica en la pared de la arteria carótida y es un factor de riesgo importante para el accidente cerebral vascular (ACV) isquémico. Este estudio describe la importancia de los exámenes de diagnóstico por imágenes utilizados en odontología para la identificación precoz de placas de ateroma en la arteria carótida interna, a nivel extracraneal e intracraneal. Un paciente masculino fue remitido a una clínica de radiología para realizar una radiografía panorámica (RP) y tomografía computarizada de haz cónico (TCHC) para analizar opciones de tratamiento. En el RP y TCHC se observó una imagen radiopaca, sugestiva de ateroma en la arteria carótida, extracraneal, en el lado derecho. El diagnóstico fue confirmado por ultrasonido DOPPLER color carotídeo. En el TCHC, también se observó la presencia de calcificaciones en la arteria carótida interna, intracraneal. Los exámenes de imagenología diagnóstica utilizados en odontología permiten la identificación de individuos asintomáticos, lo que facilita la intervención temprana y la consiguiente reducción en el riesgo de ACV isquémico.

PALABRAS CLAVE: tomografía computarizada de haz cónico, radiografía panorámica, ultrasonido DOPPLER color, aterosclerosis.

\section{REFERENCES}

Ahmad, M.; Madden, R. \& Perez, L. Triticeous cartilage: prevalence on panoramic radiographs and diagnostic criteria. Oral Surg. Oral Med. Oral Pathol. Oral Radiol. Endod., 99(2):225-30, 2005.

Almog, D. M.; Padberg, F. T. Jr.; Carmel, G. \& Friedlander, A. H. Previously unappreciated carotid artery stenosis diagnosed by cone beam computerized tomography. J. Oral Maxillofac. Surg., 71(4):702-5, 2013.

Ardakani, F. E.; Ardakani, M. A.; Mohammadi, Z. \& Sheikhha, M. $\mathrm{H}$. Evaluating calcified carotid artery atheromas in panoramic radiographs of patients with type 2 diabetes mellitus. Oral Radiol., 23(1):6-9, 2007.

Carter, L. C.; Haller, A. D.; Nadarajah, V.; Calamel, A. D. \& Aguirre, A. Use of panoramic radiography among an ambulatory dental population to detect patients at risk of stroke. J. Am. Dent. Assoc., 128(7):977-84, 1997.

Damaskos, S.; Aartman, I. H.; Tsiklakis, K.; van der Stelt, P. \& Berkhout, W. E. Association between extra- and intracranial calcifications of the internal carotid artery: a CBCT imaging study. Dentomaxillofac. Radiol., 44(5): 20140432, 2015.

Ertas, E. T. \& Sisman, Y. Detection of incidental carotid artery calcifications during dental examinations: panoramic radiography as an important aid in dentistry. Oral Surg. Oral Med. Oral Pathol. Oral Radiol. Endod., 112(4):e11-7, 2011.

Falk, E.; Shah, P. K. \& Fuster, V. Coronary plaque disruption. Circulation, 92(3):657-71, 1995.

Friedlander, A. H. \& Altman, L. Carotid artery atheromas in postmenopausal women. Their prevalence on panoramic radiographs and their relationship to atherogenic risk factors. J. Am. Dent. Assoc., 132(8):1130-6, 2001.

Friedlander, A. H. \& Gratt, B. M. Panoramic dental radiography as an aid in detecting patients at risk for stroke. J. Oral Maxillofac. Surg., 52(12):1257-62, 1994.

Friedlander, A. H.; Garrett, N. R. \& Norman, D. C. The prevalence of calcified carotid artery atheromas on the panoramic radiographs of patients with type 2 diabetes mellitus. J. Am. Dent. Assoc., 133(11):1516-23, 2002.

Friedlander, A. H.; Liebeskind, D. S.; Tran, H. Q. \& Mallya, S. M. What are the potential implications of identifying intracranial internal carotid artery atherosclerotic lesions on cone-beam computed tomography? A systematic review and illustrative case studies. J. Oral Maxillofac. Surg., 72(11):2167-77, 2014.

Garoff, M.; Johansson, E.; Ahlqvist, J.; Amerlöv, C.; Levring Jäghangen, E. \& Wester, P. Calcium quantity in carotid plaques: detection in panoramic radiographs and association with degree of stenosis. Oral Surg. Oral Med. Oral Pathol. Oral Radiol., 120(2):269-74, 2015.

Griniatsos, J.; Damaskos, S.; Tsekouras, N.; Klonaris, C. \& Georgopoulos, S. Correlation of calcified carotid plaquesdetected by panoramic radiograph with risk factors for stroke development. Oral Surg. Oral Med. Oral Pathol. Oral Radiol. Endod., 108(4):600-3, 2009.

Lee, J. S.; Kim, O. S.; Chung, H. J.; Kim, Y. J.; Kweon, S. S.; Lee, Y. H., Shin, M. H. \& Yoon, S. J. The correlation of carotid artery calcification on panoramic radiographs and determination of carotid artery atherosclerosis with ultrasonography. Oral Surg. Oral Med. Oral Pathol. Oral Radiol., 118(6):739-45, 2014.

Manzi, F. R.; Bóscolo, F. N.; de Almeida, S. M. \& Haiter Neto, F. Panoramic radiography as an auxiliary in detecting patients at risk for cerebrovascular accident (CVA): a case report. J. Oral Sci., 45(3):177-80, 2003. 
VILLORIA, E. M.; SOUKI, B. Q.; ANTUNES, F. L.; CASTRO, I. K.; SPYRIDES, K. S. \& SOARES, R. V. Panoramic radiography and cone beam computed tomography in the early diagnosis of atheroma in the extracranial and intracranial carotid artery: A case report. Int. J. Odontostomat., 13(1):75-81, 2019.

Pette, G. A.; Norkin, F. J.; Ganeles, J.; Hardigan, P.; Lask, E.; Zfaz, S. \& Parker, W. Incidental findings from a retrospective study of 318 cone beam computed tomography consultation reports. Int. J. Oral Maxillofac. Implants, 27(3):595-603, 2012.

Ritter, J. C. \& Tyrrell, M. R. The current management of carotid atherosclerotic disease: who, when and how? Interact. Cardiovasc. Thorac. Surg., 16(3):339-46, 2013.

Rothwell, P. M.; Eliasziw, M.; Gutnikov, S. A.; Fox, A. J.; Taylor, D. W.; Mayberg, M. R.; Warlow, C. P.; Barnet, H. J. \& Carotid Endarterectomy Trialists' Collaboration. Analysis of pooled data from the randomised controlled trials of endarterectomy for symptomatic carotid stenosis. Lancet, 361(9352):107-16, 2003.

Silva, A. I. V.; Nejaim, Y.; Manzi, F. R. \& Haiter Neto, F. Diagnóstico diferencial de cartilagem tritícea calcificada com doença ateroesclerótica - ateroma. Rev. Odontol. Bras. Cent., 21(56):480-3, 2012.

Tamura, T.; Inui, M.; Nakase, M.; Nakamura, S.; Okumura, K. \& Tagawa, T. Clinicostatistical study of carotid calcification on panoramic radiographs. Oral Dis., 11(5):314-7, 2005.
Corresponding author:

Eduardo Murad Villoria

Pontificial Catholic University of Minas Gerais (PUC Minas)

Graduate Program in Dentistry

Av. Dom José Gaspar, 500

Prédio 46, sala 101 - Coração Eucarístico

Belo Horizonte - MG

CEP: 30535-901

BRAZIL

E-mail: d.villoria82@yahoo.com.br

Received: 23-08-2018

Accepted: 27-11-2018 